\title{
Non-Cytotoxic Agarose/Hydroxyapatite Composite Scaffolds for Drug Release
}

\author{
Markus Witzler ${ }^{1,2}{ }^{\oplus}$, Patrick Frank Ottensmeyer ${ }^{1}$, Martin Gericke ${ }^{2}{ }^{\oplus}$, Thomas Heinze ${ }^{2}$, \\ Edda Tobiasch ${ }^{1}$ and Margit Schulze ${ }^{1, *(D)}$ \\ 1 Department of Natural Sciences, Bonn-Rhein-Sieg University of Applied Sciences, von-Liebig-Str. 20, \\ 53359 Rheinbach, Germany \\ 2 Institute of Organic Chemistry and Macromolecular Chemistry, Center of Excellence of Polysaccharide \\ Research, Friedrich Schiller University of Jena, Humboldtstr. 10, 07743 Jena, Germany \\ * Correspondence: margit.schulze@h-brs.de; Tel.: +49-2241-865-566
}

Received: 6 July 2019; Accepted: 18 July 2019 ; Published: 21 July 2019

\begin{abstract}
Healing of large bone defects requires implants or scaffolds that provide structural guidance for cell growth, differentiation, and vascularization. In the present work, an agarose-hydroxyapatite composite scaffold was developed that acts not only as a 3D matrix, but also as a release system. Hydroxyapatite (HA) was incorporated into the agarose gels in situ in various ratios by a simple procedure consisting of precipitation, cooling, washing, and drying. The resulting gels were characterized regarding composition, porosity, mechanical properties, and biocompatibility. A pure phase of carbonated HA was identified in the scaffolds, which had pore sizes of up to several hundred micrometers. Mechanical testing revealed elastic moduli of up to 2.8 MPa for lyophilized composites. MTT testing on Lw35human mesenchymal stem cells (hMSCs) and osteosarcoma MG-63 cells proved the biocompatibility of the scaffolds. Furthermore, scaffolds were loaded with model drug compounds for guided hMSC differentiation. Different release kinetic models were evaluated for adenosine $5^{\prime}$-triphosphate (ATP) and suramin, and data showed a sustained release behavior over four days.
\end{abstract}

Keywords: bone tissue engineering; agarose; hydroxyapatite; biocomposite; hydrogel; drug release

\section{Introduction}

Bone infections, bone cancer, or major injuries can cause large bone defects of critical size [1,2]. In order to repair these large bone defects, bone-grafting materials such as autografts and allografts are used [3,4]. However, due to their limitations such as rejection rate, limited availability, and possible disease transmission, synthetic scaffolds are in the spotlight of current tissue engineering research [5].

Combining the scaffolds with human mesenchymal stem cells (hMSCs) that can be isolated from different sources such as bone marrow, umbilical cord, or fat tissue is of great interest. Since hMSCs originate from adult tissues, they do not cause severe ethical concerns such as embryonic stem cells. Contrary to pluripotent stem cells, hMSCs do not carry the risk of teratoma formation due to their limited plasticity [6]. Favorable for the use of hMSCs in bone reconstructive therapies is that the stem cells have the capacity to differentiate towards osteoblasts, which is the cell type mainly accountable for bone formation [7]. Moreover, it is possible to differentiate the hMSCs in vitro. This enables therapies where osteoblast precursors or the mature osteoblasts are differentiated on scaffolds. Since specific purinergic receptors are up- or down-regulated during osteogenic differentiation in vitro [8], signaling via these receptors can enhance osteogenesis [9]. The highly-conserved family of the purinergic receptors is divided into three subfamilies, the P1, P2X, and P2Y receptors. They use extracellular nucleotides as signaling molecules [10]. The four members of the P1 subfamily are G-protein coupled 
receptors that are activated by adenosine. The seven $\mathrm{P} 2 \mathrm{X}$ receptors are ion-channels and are activated upon binding of ATP. The eight P2Y receptors are also G-protein coupled receptors and are activated by ATP, ADP, UTP, or UDP. Specific artificial ligands for these receptors are available and can be used to guide the cells into the osteogenic lineage [11].

Materials used for bone regeneration should be biocompatible, biodegradable, non-cytotoxic, and should enhance cell adhesion and proliferation. Most scaffolds presented in recent studies are made from either (bio-)polymers, (bio-)ceramics, or polymer/ceramic composites [1,5,12,13]. The latter combine positive effects from both types, while partly overcoming their respective disadvantages [14]. Natural bone itself is a composite of about 70\% inorganic hydroxyapatite (HA) and $30 \%$ collagen type I, combining the stiffness of HA and the flexibility of collagen $[15,16]$. Calcium phosphates that resemble original bone cements, such as tricalcium phosphates (TCP), hydroxyapatite (HA), and octacalcium phosphate (OCP), are used as cements and pastes, but also as ceramic filler for polymer or hydrogel scaffolds. HA, the most stable calcium phosphate at body $\mathrm{pH}$, is used in many applications since it promotes cell adhesion and proliferation [17,18]. However, it is brittle and has a low porosity. Micro- and macro-pores, which are crucial for successful vascularization, can be introduced via several different fabrication techniques such as 3D printing, electrospinning, salt leaching, or hydrogel formation $[11,19,20]$.

Hydrogels are highly-hydrated 3D polymer structures that mimic natural extracellular matrix and their physico-chemical properties. Although scaffolds prepared from poly(vinyl alcohol), poly(acrylic acid), or natural polymers (e.g., collagen, chitosan, agarose) support fast tissue regeneration, they have low mechanical properties [21]. In contrast, polymer/ceramic composites have shown enhanced mechanical stiffness, cell adhesion, proliferation, and biodegradation [5,22]. Agarose, a natural polymer extracted from red algae, forms thermoreversible hydrogels. Upon cooling agarose solution below its setting temperature, agarose coils assemble themselves into helices, forming a porous polymeric network. Heating the gel above its melting temperature leads to a disassembly of the strands. This hysteresis loop may be repeated several times without changing the agarose's properties [23,24]. Agarose is biocompatible and is studied intensively in the field of tissue engineering, e.g., for the regeneration of neural, cartilage, skin, and bone tissue [25]. For the latter, it is often used in hybrid composite systems, where the resulting scaffolds showed a high osteoconductivity [26,27] and induced new bone formation or osteoconduction [28,29].

Mineralizing agarose hydrogels also improved the mechanical properties and wettability of the scaffolds [30]. Aside from simply mixing HA powder with the agarose solution [31-33], there are several ways for in situ mineralization of HA inside the hydrogel that lead to more homogeneous scaffold materials. A common way is the wet alternate soaking process, where thin hydrogels are repeatedly placed in calcium- and phosphate-containing solutions for more than 10 cycles. This yields mineralized hydrogels, but is very time consuming due to the number of soaking and washing steps. Additionally, only thin gels can be homogeneously mineralized [26,29,34]. Another approach is the precipitation of HA inside an agarose solution containing phosphate by dropwise addition of calcium solution [30] or by the change of the $\mathrm{pH}$ value after hydrogel casting [35]. These techniques are less time consuming than alternate soaking, but may have more complex experimental setups, do not control the phase of calcium phosphate that is formed, or do not allow the easy incorporation of active ingredients.

Apart from giving structural guidance, the scaffold function is often combined with release properties for various kinds of bioactive ingredients such as antibiotics or growth factors and may even serve as a host compartment for cells. For example, ibuprofen and anti-osteoporosis drug zoledronic acid were released in vitro over three days from an agarose-hydroxyapatite scaffold and chitosan spheres [33]. Zoledronic acid (which has a high affinity to calcium phosphates) and recombinant human bone morphogenic protein-2 (rhBMP-2) were released in vitro and in vivo from a gelatin $/ \mathrm{CaSO}_{4} /$ hydroxyapatite system over four weeks [36]. rhBMP-2 was also used and was released in vitro from MSC-loaded collagen scaffolds and alginate/chitosan/hydroxyapatite scaffolds over 14 
and 21 days, respectively [37]. The release behavior of the antibiotic amoxicillin from agarose-coated hydroxyapatite was investigated, as well, and a prolonged release of about three days was found [38]. However, only a few data on release kinetics were reported for these bone scaffold systems.

The current research adds to the broad field of tissue engineering and drug delivery. We present a fast and easy approach for preparing agarose/hydroxyapatite composite scaffolds. In detail, the composite preparation process is studied regarding the influence on the scaffold morphology, porosity, and their correlation to swelling behavior and mechanical stability. The biocompatibility of the scaffolds and the drug release kinetics of two model drugs structurally similar to osteo-influencing ingredients are also investigated and evaluated via different kinetic models.

\section{Results and Discussion}

During preparation, HA immediately precipitated as soon as the alkaline phosphate solution was added to the calcium-containing agarose solution, resulting in a homogeneous slurry that was used for casting the gels. Pure agarose solution remained transparent, solidifying upon cooling. All cast gels were of a cylindrical shape and were cut into approximately $10 \mathrm{~mm}$-high cylinders for most analyses. AG100HA0 hydrogels were translucent, while added HA led to opaque, white gels with AG33HA67 having a polymer/ceramic ratio close to the original bone composition.

\subsection{Scaffold Characterization}

\subsubsection{X-Ray Diffraction}

X-ray diffractograms of HA and AG33HA67 composite are shown in Figure 1. Reflexes of HA corresponded well to a (carbonated) HA phase (JCPDS PDF No. 09-432) and were indexed according to the literature [18]. The lyophilized scaffold showed much broader reflexes as it lacked thermal treatment; however, indexing of the major signals revealed also an HA phase.

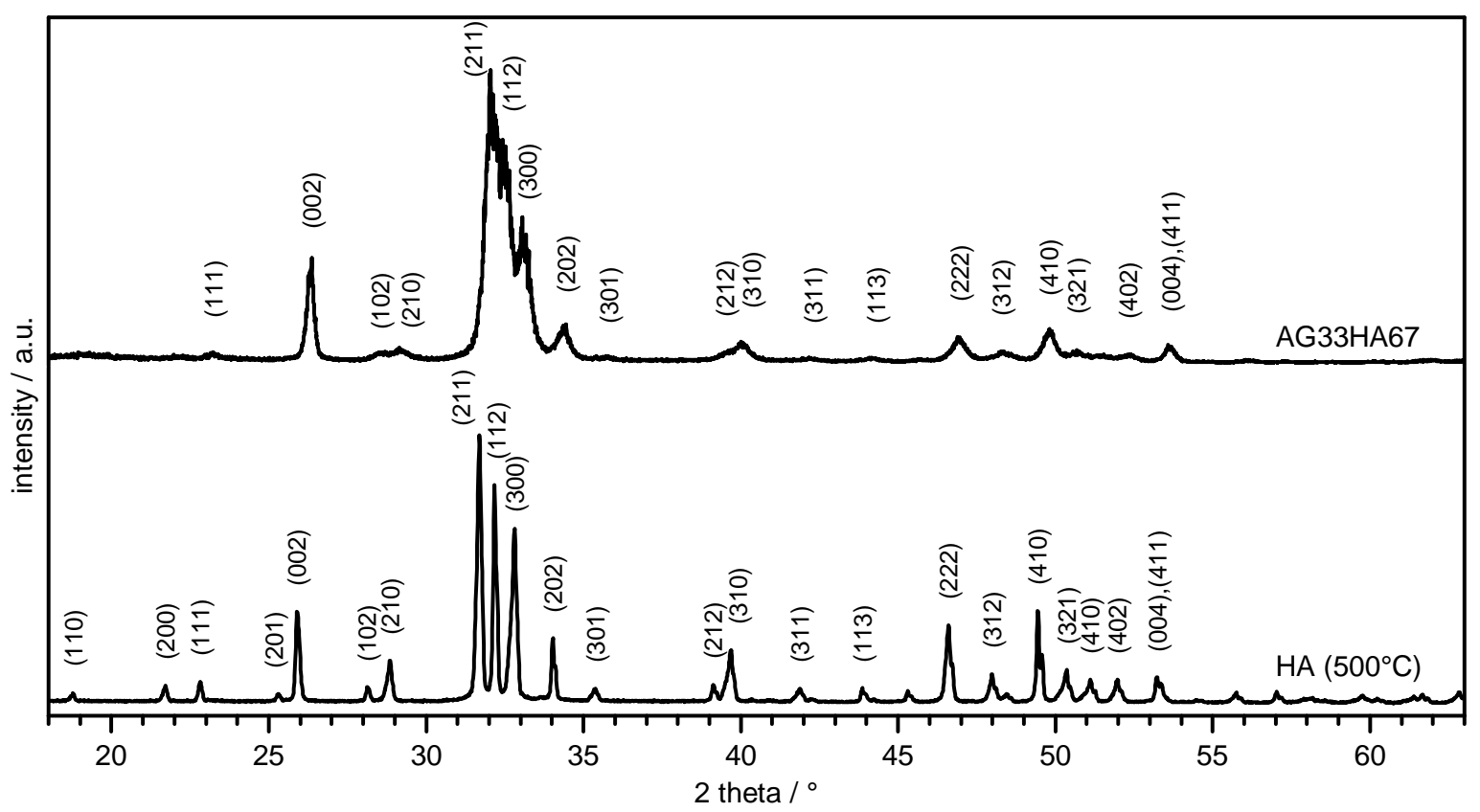

Figure 1. X-ray diffraction of hydroxyapatite (HA) dried at $500{ }^{\circ} \mathrm{C}$ and lyophilized agarose/HA composite (AG33HA67).

Crystallite sizes of the (002) plane were $1.04 \mathrm{~nm}$ for pure hydroxyapatite and $0.55 \mathrm{~nm}$ in the composite. The degree of crystallinity was $92.1 \%$ and $37.8 \%$, respectively. A small shift of the signals towards lower $2 \theta$ values was observable in the composite, indicating an influence of the agarose network on the crystallization of HA. This corresponds well to a previous study, where the agarose 
composite also showed shifted reflexes, and the degree of crystallinity was between 47 and $24 \%$. The shifts in diffraction angle were due to the preferred crystal growth along the agarose gel network, which resulted in a slight distortion of the crystal lattice [30].

\subsubsection{Infrared Spectroscopy}

FT-IR spectra of pure agarose, hydroxyapatite, and the composite are shown in Figure 2 and were used for the identification of the composite's components. It clearly showed the main characteristic bands of both carbonated hydroxyapatite and agarose, confirming the presence of both. In detail, a broad $\mathrm{OH}$ stretching band between 3000 and $3600 \mathrm{~cm}^{-1}$ and a shoulder signal of $v_{S}$ free $\mathrm{OH}$ at $3572 \mathrm{~cm}^{-1}$ can be identified in all samples. Aliphatic C-H asymmetric stretching at $2925 \mathrm{~cm}^{-1}$ originating from the polysaccharide's methylene groups can be found in agarose and the composite. $\mathrm{OH}$ deformation vibration at $1636 \mathrm{~cm}^{-1}$ may be overlapped by adsorbed bending water $[39,40]$. The signals at $1406 \mathrm{~cm}^{-1}$ and $893 \mathrm{~cm}^{-1}$ originated from in-plane $\mathrm{O}-\mathrm{H}$ deformation coupled with $\mathrm{C}-\mathrm{H}$ wagging in agarose and from $v_{3} \mathrm{CO}_{3}{ }^{2-}$ in carbonated $\mathrm{HA}$, respectively [39-41]. A weak signal at $1154 \mathrm{~cm}^{-1}$ from C-O-C acetal vibration in agarose was also observed as a shoulder in the composite [40]. In $\mathrm{HA}$ and the composite, there were very prominent phosphate triply-degenerated asymmetric $\mathrm{P}-\mathrm{O}$ stretching $v_{3 a-c}$ at 1087,1046 , and $1032 \mathrm{~cm}^{-1}[18,41]$. Weak $\mathrm{CH}_{2}$ twisting at $930 \mathrm{~cm}^{-1}$ originated from the agarose matrix [40]. The small signals at 873 and $668 \mathrm{~cm}^{-1}$ in the HA can be assigned to a $v_{2}$ and $v_{4}$ mode of carbonate, respectively [18,42]. Symmetric $n_{1} \mathrm{P}-\mathrm{O}$ stretching at $962 \mathrm{~cm}^{-1}, v_{4} \mathrm{O}-\mathrm{P}-\mathrm{O}$ bending at 602 and $561 \mathrm{~cm}^{-1}$, and liberational mode $v_{L}$ of $\mathrm{OH}$ at $632 \mathrm{~cm}^{-1}[18,42]$ were also present in both HA and the composite. The absence of any other signals than those of agarose and (carbonated) HA led to the conclusion that the composite did not contain any other mineral phases or impurities.

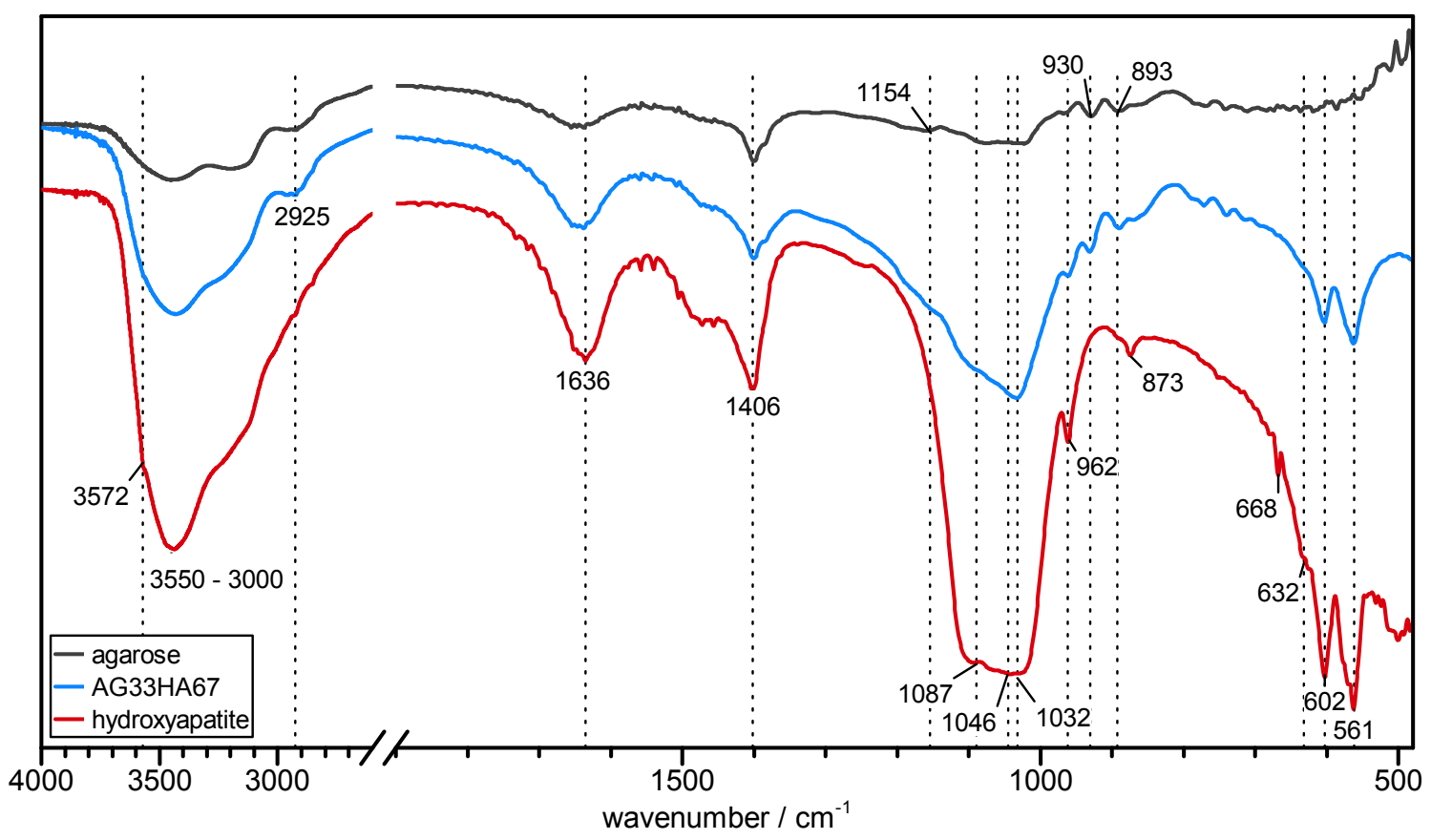

Figure 2. FT-IR spectra of agarose (black), hydroxyapatite (red), and agarose/hydroxyapatite composite (AG33HA67; blue). 


\subsubsection{Porosity}

BET measurements (Table 1) were performed to determine differences in the specific surface area of the samples, thus providing information on the respective microstructure. Lyophilization yielded a similar specific surface area $A_{s p}$ of $24-32 \mathrm{~m}^{2} \mathrm{~g}^{-1}$ for all samples regardless of composition, although $A_{s p}$ increased with the amount of added HA. These data concur with previously-published results, where similar results were found for lyophilized samples of mixed-in nano-HA in agarose solution before gelling [43] and microwave-assisted HA-AG composites [44]. Supercritical drying results in 3-6-times higher specific surface areas of $98-144 \mathrm{~m}^{2} \mathrm{~g}^{-1}$. Here, $A_{s p}$ decreased with the addition of more hydroxyapatite, with agarose gels having a significantly higher $\left(p<5 \times 10^{-6}\right.$ at the $95 \%$ level) specific surface area than both composite gels after supercritical drying.

Table 1. Specific surface area measured by BET of lyophilized (LYO) and supercritically-dried (SCD) samples. ${ }^{*}$ : significant difference at the $95 \%$ level $\left(p<5 \times 10^{-6}\right)$ against both composites, ${ }^{* *}$ : significant difference at the $95 \%$ level $(p=0.00161)$ against pure agarose.

\begin{tabular}{lllllll}
\hline & AG100HA0 & \multicolumn{2}{l}{ AG50HA50 } & \multicolumn{2}{l}{ AG33HA67 } \\
\hline & LYO & SCD $^{*}$ & LYO & SCD & LYO & LC \\
$A_{s p}\left(\mathrm{~m}^{2} \mathrm{~g}^{-1}\right)$ & $24 \pm 1$ & $144 \pm 9$ & $28 \pm 2$ & $101 \pm 1$ & $32 \pm 4$ & $98 \pm 1$ \\
\hline
\end{tabular}

Scanning electron microscopy (SEM) was also used to evaluate the internal structure of the lyophilized (LYO) and supercritically-dried (SCD) gels and to determine pore sizes. Figure 3a-c shows LYO AG100HA0, and Figure 3d-f shows the SCD agarose sample. Figure 3g-i shows the LYO AG33HA67 composite and Figure 3k-m the SCD composite sample. At lower magnification, both lyophilized samples exhibited large pores in the range of several hundred micrometers (Figure 3a,g). This was due to the growth of ice crystals during the freezing process, forcing the agarose/composite to form layers. These layers or sheets (up to $2 \mu \mathrm{m}$ in thickness) can be seen at higher magnifications (Figure $3 b, c, h, i)$. In the composite, additional particles of HA were visible on and between the agarose sheets. These particles were between 150 and $500 \mathrm{~nm}$ in diameter (Figure $3 \mathrm{~h}, \mathrm{i}$ ). In contrast to the lyophilized samples, the supercritically-dried ones did not exhibit large pores at lower magnifications, but seemed to be very homogeneous (Figure $3 \mathrm{~d}, \mathrm{k}$ ). At higher magnifications, highly porous and very fine network structures (strand thickness about $35 \mathrm{~nm}$ ) became visible, with no differences between the pure agarose and the composite. Interestingly, no distinct HA particles could be seen in the network structure, which suggests a coating of the agarose strands with hydroxyapatite. This was confirmed by EDX analysis (Figure A1), where a homogeneous distribution of carbon, calcium, and phosphorus was found throughout the scaffold.

The SEM observations matched the results measured by BET, which showed a much higher specific surface area for SCD samples. While the internal structure was destroyed during lyophilization, leading to larger pore sizes, supercritical drying preserved the fine hydrogel network structure, which has been reported for pure polysaccharide and mixed-in calcium phosphate systems before [45-47], but not for composites with in situ precipitated calcium phosphates. However, larger pores in the range of several hundred micrometer are needed in order to promote osteogenesis [48], which is why further testing was done only with lyophilized scaffolds. 


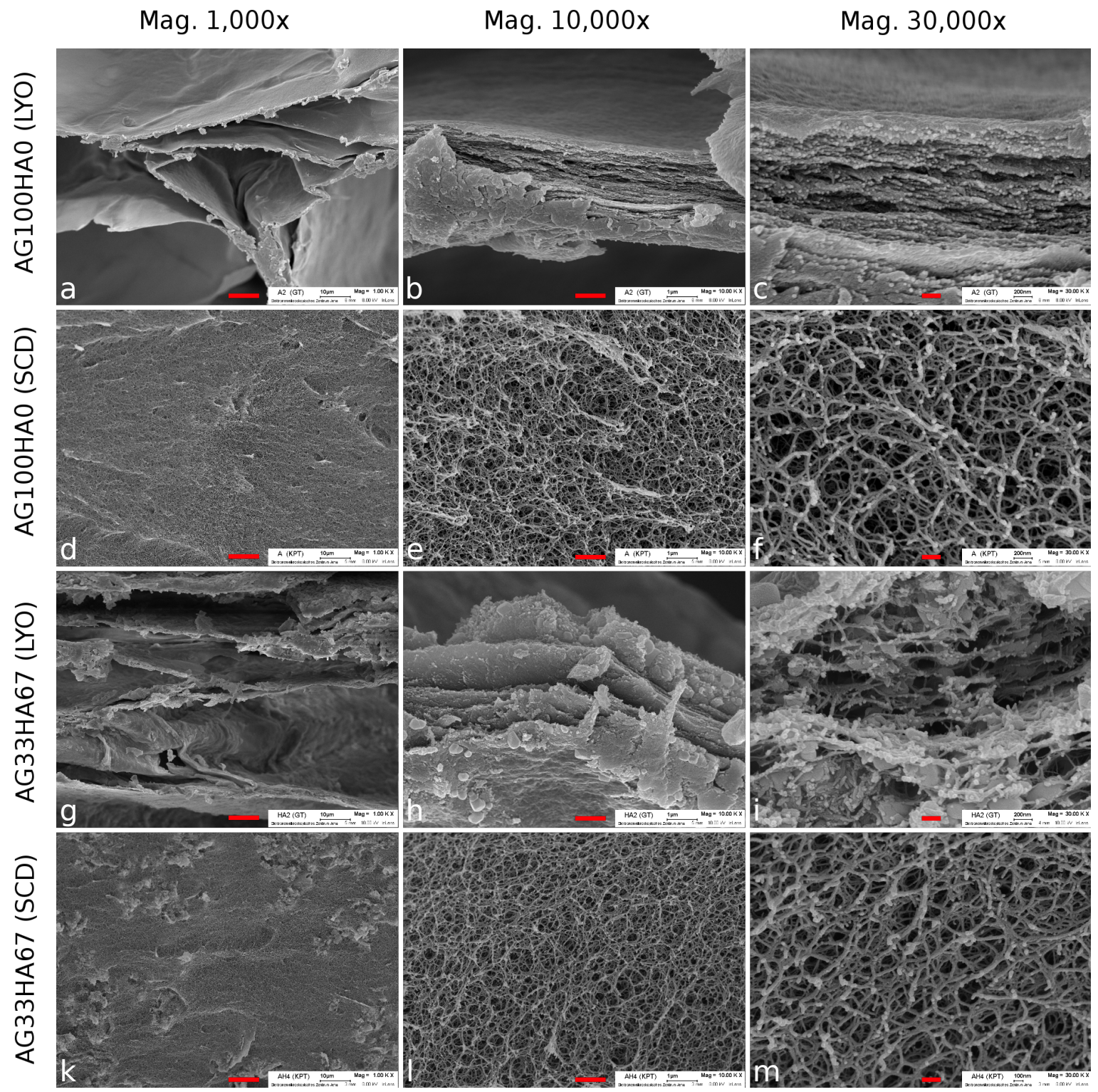

Figure 3. SEM images of agarose lyophilized (LYO; $(\mathbf{a}-\mathbf{c}))$ and supercritically-dried $(\mathrm{SCD} ;(\mathbf{d}-\mathbf{f}))$ and AG33HA67 composite LYO (g-i) and SCD $(\mathbf{k}-\mathbf{m})$ at three different magnifications. The scale bar is $10 \mu \mathrm{m}$ (left), $1 \mu \mathrm{m}$ (middle), and $0.2 \mu \mathrm{m}$ (right), respectively.

\subsubsection{Shrinking and Swelling}

Shrinking and swelling of the scaffold are important characteristics, as they influence the mechanical properties, drug release, and handling after preparation [32]. Shrinking behavior was tested with drying at $40^{\circ} \mathrm{C}$ under vacuum (VD) or lyophilization (LYO). Upon vacuum drying, the original geometry collapsed completely regardless of the composition (Figure $4 a, b$ ); only $2.5-21 \%$ of the original volume remained (Figure 4e). Lyophilization, however, resulted in increased form stability (Figure 4a,b), with 52\% (AG100HA0), 69\% (AG50HA50), and 85\% (AG33HA67) of the respective original volume remaining (Figure 4e). Both drying methods removed most of the water from the hydrogels, which was indicated by the mass loss (Figure 4e). AG100HA0, a hydrogel with $2 \% w t$ polymer, lost about $98 \%$ of its mass, AG50HA50 (2\%wt AG, $2 \%$ wt HA, and ca. $3 \%$ wt $\mathrm{NaNO}_{3}$ in the unwashed hydrogel) about $93 \%$ of its mass, and AG33HA67 (2\%wt AG, $4 \%$ wt HA, and ca. $6 \%$ wt $\mathrm{NaNO}_{3}$ in the unwashed hydrogel about $88 \%$ of its mass. 
Swelling tests of dried gels and native hydrogels at different $\mathrm{pH}(5.0,7.4$, and 9.0) for up to $48 \mathrm{~h}$ showed no $\mathrm{pH}$-dependency for any sample. Additionally, there were no differences between measurements after $6 \mathrm{~h}, 24 \mathrm{~h}$, and $48 \mathrm{~h}$, indicating a fast re-swelling of dried samples (see complete data in Figure A2). Native (undried) hydrogels exhibited almost no swelling (not more than $5 \%$ ), as they took up less than $1 \%$ of water (Figure $4 \mathrm{c}, \mathrm{d}$ ). Vacuum-dried samples had the highest swelling ranging from $230 \%$ for AG100HA0 to $68 \%$ for AG33HA67 (Figure 4c). The water uptake for AG100HA0 (388\%) was almost 10-times higher than for AG50HA50 (41\%) and even lower for AG33HA67 (22\%). The good form stability visually observed on lyophilized samples was confirmed by a very low swelling in volume (less than $17 \%$ for all samples), but a very high uptake of water (2310\% for AG100HA0). Again, less water uptake was observed for samples with a higher hydroxyapatite content $(775 \%$ and $553 \%$, respectively) (Figure $4 \mathrm{~d}$ ).
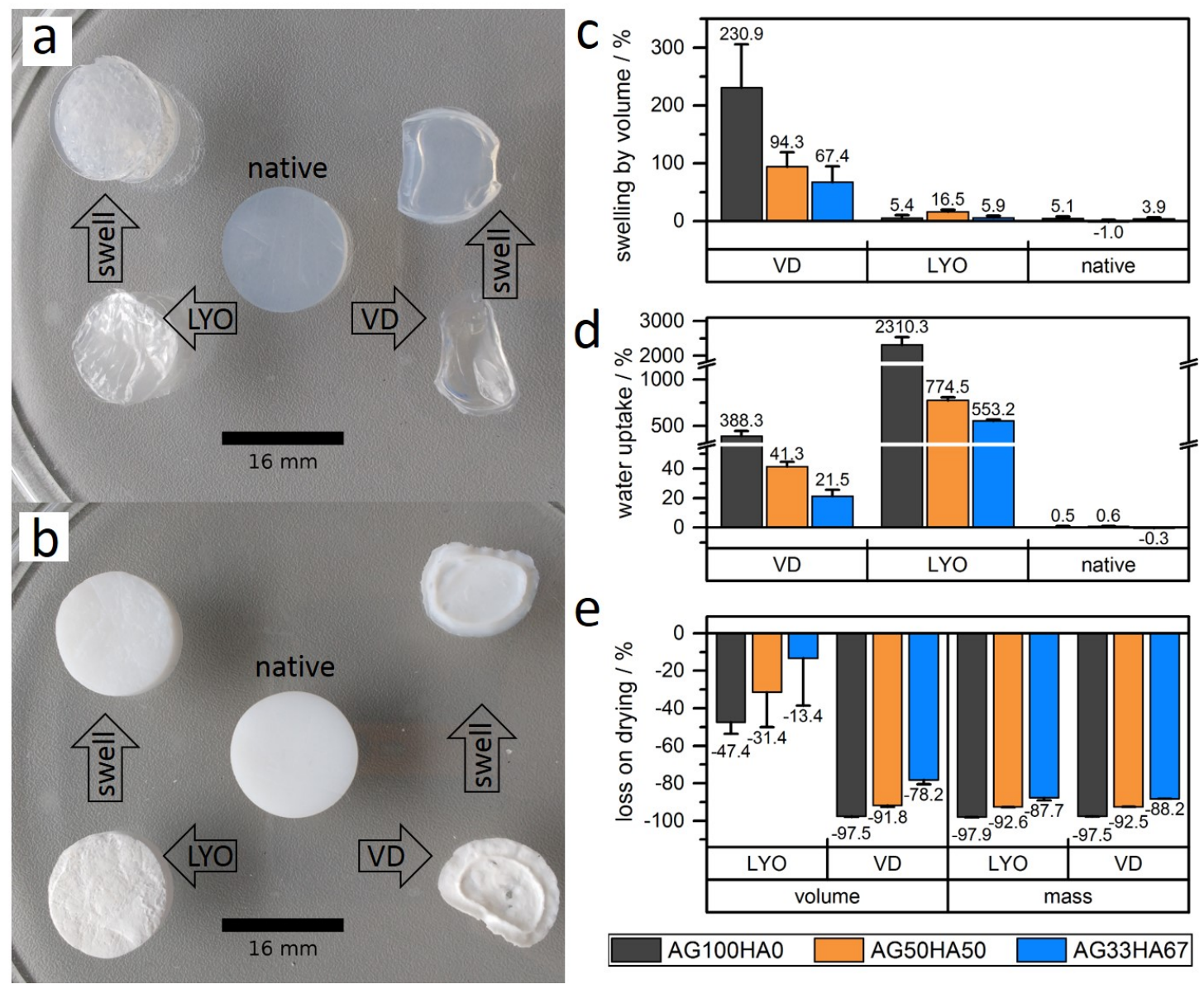

Figure 4. Images of (a) agarose hydrogel (AG100HA0) and (b) composite hydrogel (AG33HA67) in the native state, lyophilized (LYO), or vacuum dried (VD) and after reswelling of the dried gels. Comparison of (c) swelling, (d) water uptake, and (e) volume and mass loss for dried and native gels.

\subsubsection{Mechanical Properties}

Mechanical compression testing revealed a hyperelastic behavior for native and rehydrated hydrogels. Lyophilized gels followed a linear elastic behavior under strains below $15 \%$. Compressive strength was derived from the first maximum of the strain-stress curve, where the respective strain was also noted. Elastic moduli for lyophilized samples were derived from Hooke's law in the range below $10 \%$ strain. For hyperelastic samples, the behavior could be better approximated with a neo-Hooke model, giving a linear dependency in the stress $\left(\lambda-1 / \lambda^{2}\right)$ curves with $\lambda=L / L_{0}$ being the stretch ratio (Figure 5) [49]. Elastic moduli as a measure for stiffness ranged around $40-50 \mathrm{kPa}$ for native 
gels, which is a typical value for hydrogels [49,50]. After lyophilization, stiffness increased drastically with increasing amounts of hydroxyapatite, ranging from $140 \mathrm{kPa}$ for AG100HA0 up to $2880 \mathrm{kPa}$ for AG33HA67. Rehydrated cryogels lost their stability, yielding compressive moduli around 2-6 kPa and thus ranging even below the native hydrogels (Figure 5). The composition of hydrogels did not have a significant influence on compressive strength and strain at that stress. All native gels were around $50 \mathrm{kPa}$ and $30 \%$ strain, while rehydrated gels were around $3 \mathrm{kPa}$ and $20 \%$ strain. Lyophilized gels had higher compressive strengths with increasing amount of hydroxyapatite; however, the strain at that stress did not change significantly.

Literature data of such systems are very vague, because many groups used different approaches to measure stress, strain, and modulus. For a $2 \%$ agarose hydrogel, a Young's modulus of $28 \mathrm{kPa}$ using a neo-Hooke model has been reported [50], while other different groups reached elastic moduli between 2 and $300 \mathrm{kPa}$ for $2 \%$ agarose gels [49]. For a comparable composite, elastic moduli for a system of $40 \%$ agarose and $60 \%$ calcium phosphate measured at $10 \%, 25 \%$, and $50 \%$ strain of $8.6,24.8$, and $60.9 \mathrm{MPa}$, respectively, have been published [30]. In contrast, the moduli presented in the current study were calculated between 2 and $10 \%$ strain and showed a different stress-strain curve, which led to these lower values. These mechanical properties, together with shrinking and swelling, have some implications on practical use. On the one side, scaffolds that have been lyophilized and rehydrated prior to implanting might not be suitable for any major load-bearing applications. However, they might be useful for filling voids and provide structural guidance for cells. Cells could easily migrate into scaffolds with larger pores, which could result in a better vascularization of the scaffold [51,52].

a

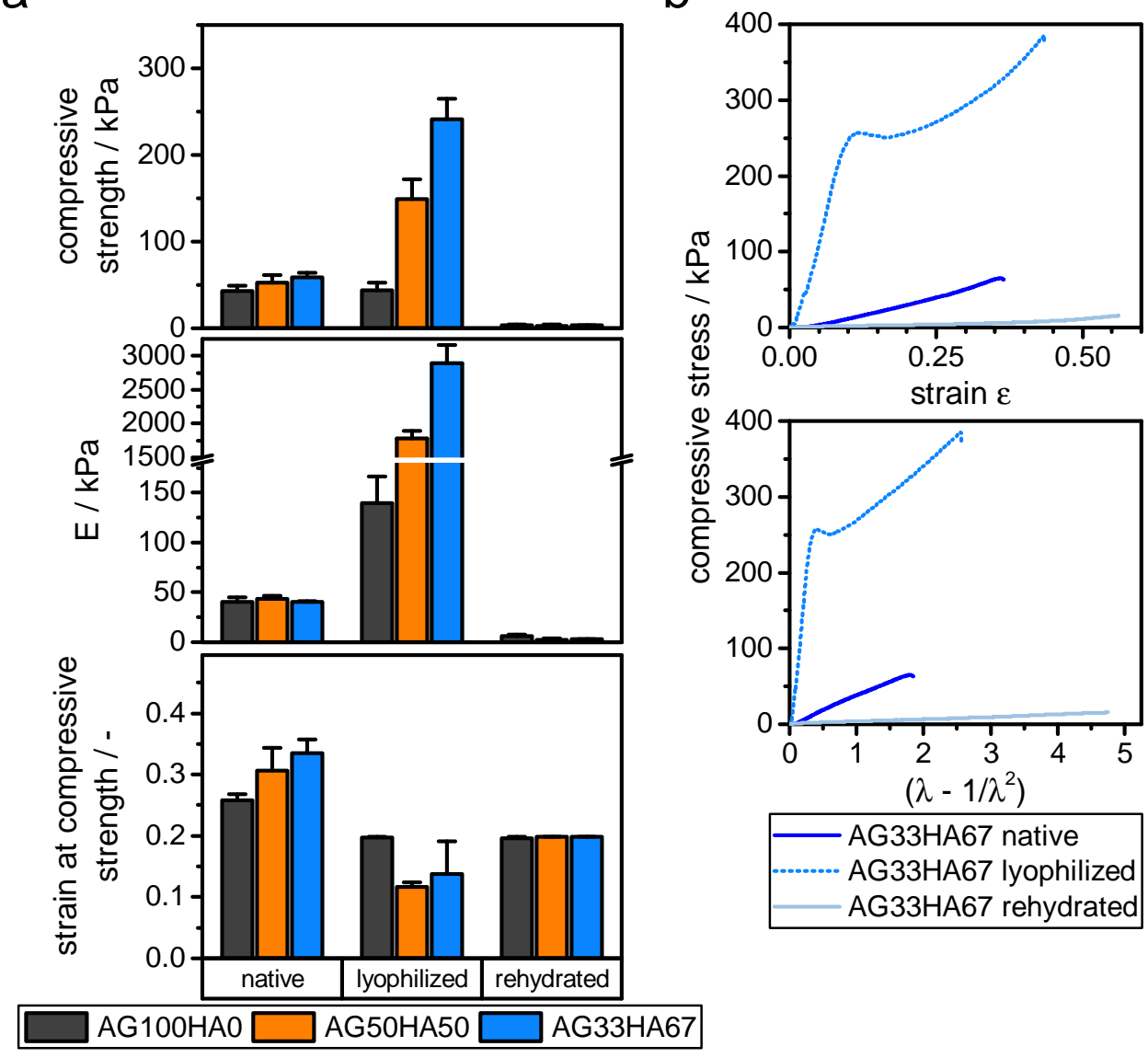

Figure 5. Compressive properties of native hydrogels, lyophilized, and rehydrated gels. (a) Compressive strength, elastic modulus $E$, and strain at compressive strength, derived from uni-axial unconfined compression $(n=6)$. (b) Typical stress-strain and stress $\left(\lambda-1 / \lambda^{2}\right)$ curves for AG33HA67 gels. 


\subsection{Biocompatibility}

In order to investigate the biocompatibility of the scaffold materials, MTT assays with scaffold-incubated media were performed on an osteosarcoma cell line and on primary hMSCs. Overall, MTT assays on hMSC (Lw35) and the osteosarcoma MG-63 cell line showed no toxic effect of the scaffolds. Cell viability of more than $95 \%$ for MG-63 cells showed that they were unaffected by all types of scaffold regardless of their composition. However, as expected, hMSC seemed to be slightly more sensitive to scaffold material. While they were rather unaffected by the pure AG scaffolds maintaining a cell viability of more than $85 \%$, AG33HA67 washed with water slightly decreased cell viability to around $70 \%$. Washing these scaffolds with PBS instead of water could retain a high cell viability of around $95 \%$ (Figure 6). This might be related to the physiological salt concentration of PBS and thus a lower gradient upon scaffold reconstitution. These results show that the materials are non-cytotoxic and are suitable for use in cell culture.

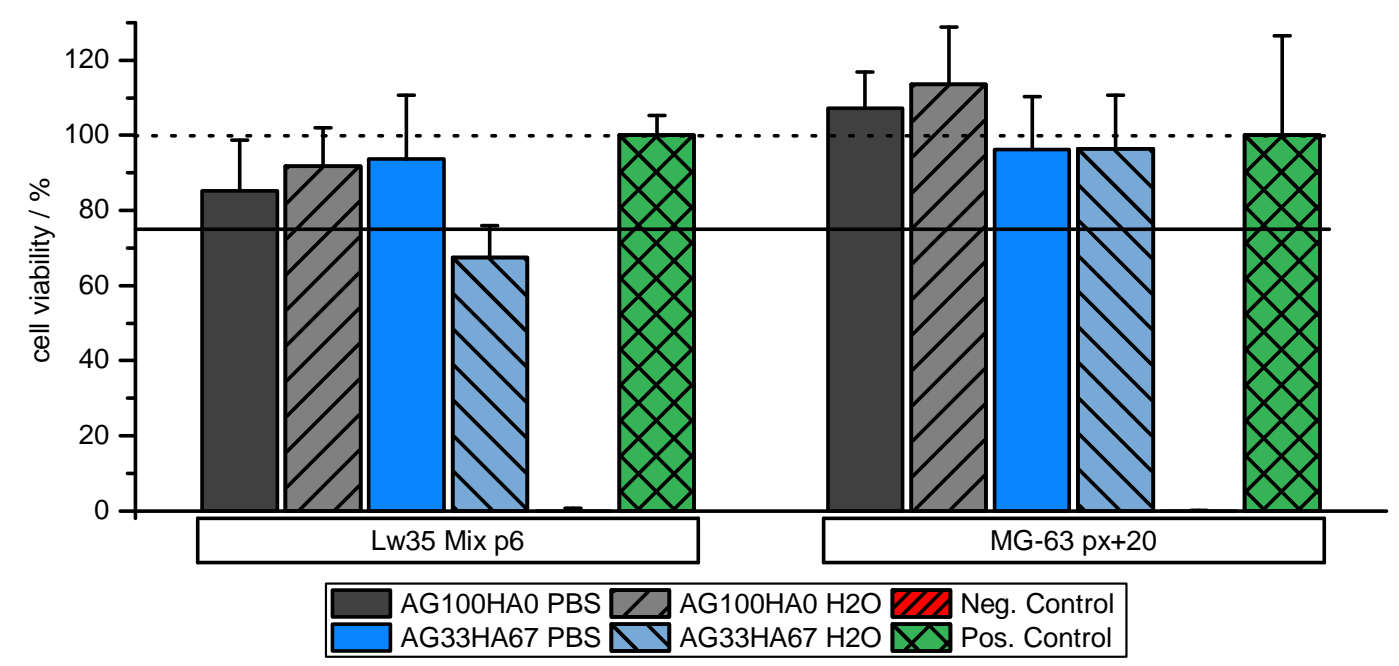

Figure 6. Cell viability of hMSCs Lw35and MG-63 cell lines on pure agarose (AG100HA0) and AG33HA67 composites. Scaffolds washed with PBS prior to MTT assay display higher cell viability. One hundred percent viability (dotted line) and 75\% viability (solid line) are marked for clarification.

\subsection{Release Studies}

Different release models, namely Weibull, first-order, and Korsmeyer-Peppas, were used in order to gain information on release kinetics. As stated in the Materials and Methods Section, the three models were selected according to their varying amount of information [53]. In the literature, if at all, usually only one fitting model is applied without showing potential differences between them. Often, only a value of how many days or hours until a specific percentage of released drug $\left(d_{x}\right)$ is given, without any release kinetics parameters. Water-soluble drugs are usually released within several hours [30,38]. ATP and suramin were chosen as model drugs in this study, as they are readily available and show structural resemblance to other P2 receptor ligands that influence osteogenic differentiation $[8,11]$.

The release profiles for ATP and suramin are depicted in Figure 7a,b, respectively. They all showed a burst release, where a major amount of the incorporated drug was released within the first $8 \mathrm{~h}$, which is a typical behavior for hydrogel systems and the release of hydrophilic drugs into aqueous media in general. For ATP, a higher amount of HA resulted in a slower release, visible in the decreased slope. Suramin release seemed to be less dependent on the material, and remarkably, the AG50HA50 scaffolds showed the lowest overall amount released after $96 \mathrm{~h}$. Table 2 summarizes the relevant parameters for the different fitting functions of both ATP and suramin release profiles. They can all be fitted with a Weibull release function with $R^{2}>0.993$ accurately describing the amount of drug $M$ at time $t$. In the case of ATP, all systems released up to about $92 \%$ of the drug, and the latency time $T$ was 
zero (within the accuracy). However, this function was not based on kinetic considerations and thus only useful for direct comparison of the different profiles for which the parameter $q$ was used. A high value of $q$ represents a slower release. It increased with increasing amount of HA in the material from 0.83 to $34 \mathrm{~h}$, indicating a slower release of the drug. This can also be derived from the decreasing value of release rate $k$ in the first-order model, while $M_{f}$, however, represents the release profiles especially up to about $85 \%$ release, but usually underestimates the maximum amount released, as it di for all three samples. In the Korsmeyer-Peppas model, the exponent $n$ is related to the release mechanism. For cylindrical systems, the Fickian model (Case I) would be at $n=0.45$, when the release is solely governed by diffusion. With $0.45<n<0.89$, there is anomalous transport behavior, where diffusion and system relaxation processes occur. After that, Case II $(n=0.89)$ and Super Case II $(n>0.89)$ models apply. The Korsmeyer-Peppas model reveals a diffusion-based mechanism for AG100HA0, while the exponents of the other samples indicate a more complex release mechanism. The low nof 0.24 for AG50HA50 may be due to physico-chemical interactions between drug and scaffold, while the $\mathrm{n}$ of 0.64 for AG33HA67 suggests an anomalous transport, sustaining the release.
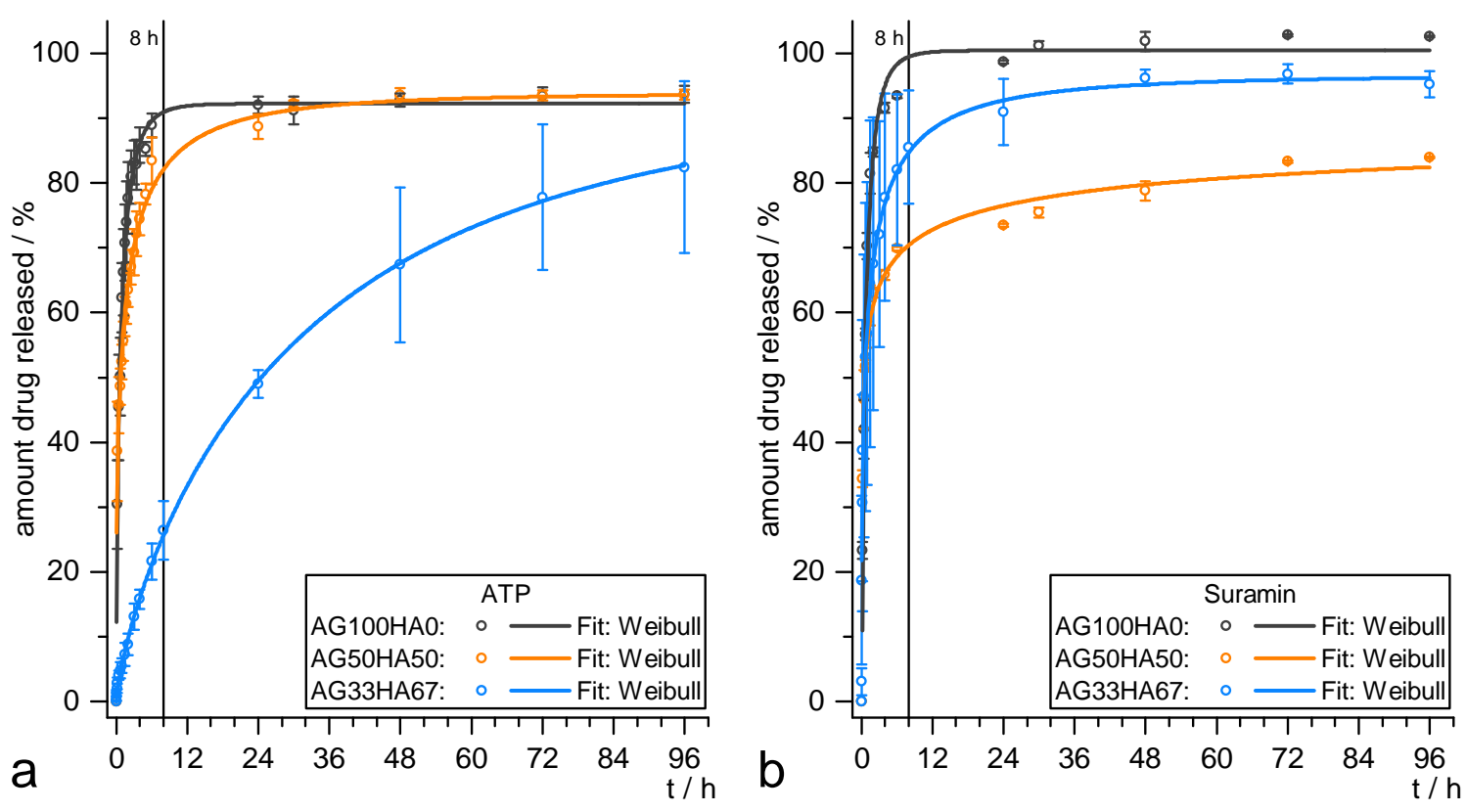

Figure 7. Release data of (a) ATP and (b) suramin from AG100HA0 (black), AG50HA50 (orange), and AG33HA67 (blue) scaffolds. Data fit: Weibull equation $M=M_{f} \cdot\left(1-e^{\frac{-(t-T)^{b}}{a}}\right)$.

In the case of suramin, none of the samples exhibited clearly sustained behavior. The Weibull model calculated an overall amount released of $90-100 \%$ with the latency times $T$ being slightly increased for AG100HA0 and AG50HA50 and being around zero for AG33HA67. Although AG50HA50 had the lowest overall release, AG33HA67 exhibited the slowest release ( $q=1.19 \mathrm{~h}$ for AG33HA67 vs. $q=0.9 \mathrm{~h}$ for AG50HA50). This was also confirmed by the first-order release rate $k=1.4 \mathrm{~h}^{-1}$ and $k=0.9 \mathrm{~h}^{-1}$ for AG50HA50 and AG33HA67, respectively. The Korsmeyer-Peppas model revealed mainly anomalous transport mechanisms for AG100HA0 and AG33HA67, and again, a low n of 0.30 for AG50HA50, indicating drug-scaffold interactions.

These results showed that both drugs were released more slowly from the system when HA was added to the scaffold. For ATP, the effect was more distinctive, which might be due to a high affinity of the ATP's triphosphate group to the scaffold's calcium ions. Suramin was less retained, although a slight decrease in the release rate was also noticed, which could be attributed to the sulfonate-calcium interaction, although the calcium sulfonates remained water-soluble [54]. Although both drugs are highly water-soluble, the release can be slowed to several days, which is longer than comparable systems previously reported in the literature [30]. On the one hand, the burst release behavior could 
be beneficial for the incorporation of anti-inflammatory or antibacterial drugs, in order to achieve a fast therapeutic effect. A prolonged release on the other hand is needed for drugs that should guide directed stem cell differentiation and need to be on site over a longer period of time.

Table 2. Release profile fitting parameters for Weibull, first-order, and Korsmeyer-Peppas equations of ATP and suramin released from different scaffolds. $n=3$.

\begin{tabular}{|c|c|c|c|c|}
\hline \multirow{2}{*}{ Drug } & \multirow{2}{*}{ Material } & \multicolumn{3}{|c|}{ Model } \\
\hline & & Weibull & First-Order & Korsmeyer-Peppas \\
\hline \multirow[t]{3}{*}{ ATP } & AG100HA0 & $\begin{array}{l}R^{2}=0.9962 \\
M_{f}=0.923 \pm 0.007 \\
T=0.06 \pm 0.06 \mathrm{~h} \\
q=0.83 \pm 0.08 \mathrm{~h}\end{array}$ & $\begin{array}{l}R^{2}=0.9808 \\
M_{f}=0.90 \pm 0.02 \\
B=0.84 \pm 0.03 \\
k=1.08 \pm 0.08 \mathrm{~h}^{-1}\end{array}$ & $\begin{array}{l}R^{2}=0.9734 \\
K=0.61 \pm 0.02 \mathrm{~h}^{-\mathrm{n}} \\
n=0.50 \pm 0.07\end{array}$ \\
\hline & AG50HA50 & $\begin{array}{l}R^{2}=0.9951 \\
M_{f}=0.94 \pm 0.02 \\
T=0.00 \pm 0.09 \mathrm{~h} \\
q=1.4 \pm 0.2 \mathrm{~h}\end{array}$ & $\begin{array}{l}R^{2}=0.9143 \\
M_{f}=0.90 \pm 0.03 \\
B=0.69 \pm 0.06 \\
k=0.48 \pm 0.09 \mathrm{~h}^{-1}\end{array}$ & $\begin{array}{l}R^{2}=0.9912 \\
K=0.532 \pm 0.003 \mathrm{~h}^{-n} \\
n=0.24 \pm 0.02\end{array}$ \\
\hline & AG33HA67 & $\begin{array}{l}R^{2}=0.9997 \\
M_{f}=0.92 \pm 0.02 \\
T=-0.04 \pm 0.04 \mathrm{~h} \\
q=34 \pm 2 \mathrm{~h}\end{array}$ & $\begin{array}{l}R^{2}=0.9964 \\
M_{f}=0.82 \pm 0.02 \\
B=0.80 \pm 0.02 \\
k=0.040 \pm 0.003 \mathrm{~h}^{-1}\end{array}$ & $\begin{array}{l}R^{2}=0.9959 \\
K=0.064 \pm 0.003 \mathrm{~h}^{-\mathrm{n}} \\
n=0.64 \pm 0.02\end{array}$ \\
\hline \multirow[t]{3}{*}{ suramin } & AG100HA0 & $\begin{array}{l}R^{2}=0.9931 \\
M_{f}=1.00 \pm 0.02 \\
T=0.17 \pm 0.05 \mathrm{~h} \\
q=0.72 \pm 0.07 \mathrm{~h}\end{array}$ & $\begin{array}{l}R^{2}=0.9902 \\
M_{f}=0.99 \pm 0.02 \\
B=0.99 \pm 0.04 \\
k=1.12 \pm 0.08 \mathrm{~h}^{-1}\end{array}$ & $\begin{array}{l}R^{2}=0.9989 \\
K=0.706 \pm 0.007 \mathrm{~h}^{-\mathrm{n}} \\
n=0.78 \pm 0.03\end{array}$ \\
\hline & AG50HA50 & $\begin{array}{l}R^{2}=0.9941 \\
M_{f}=0.90 \pm 0.08 \\
T=0.23 \pm 0.02 \mathrm{~h} \\
q=0.9 \pm 0.7 \mathrm{~h}\end{array}$ & $\begin{array}{l}R^{2}=0.9176 \\
M_{f}=0.76 \pm 0.03 \\
B=0.70 \pm 0.07 \\
k=1.4 \pm 0.3 \mathrm{~h}^{-1}\end{array}$ & $\begin{array}{l}R^{2}=0.9723 \\
K=0.56 \pm 0.01 \mathrm{~h}^{-\mathrm{n}} \\
n=0.30 \pm 0.04\end{array}$ \\
\hline & AG33HA67 & $\begin{array}{l}R^{2}=0.9987 \\
M_{f}=0.966 \pm 0.009 \\
T=0.060 \pm 0.006 \mathrm{~h} \\
q=1.19 \pm 0.09 \mathrm{~h}\end{array}$ & $\begin{array}{l}R^{2}=0.9396 \\
M_{f}=0.89 \pm 0.03 \\
B=0.77 \pm 0.05 \\
k=0.9 \pm 0.2 h^{-1}\end{array}$ & $\begin{array}{l}R^{2}=0.9501 \\
K=0.64 \pm 0.06 \mathrm{~h}^{-\mathrm{n}} \\
n=0.465 \pm 0.08\end{array}$ \\
\hline
\end{tabular}

\section{Materials and Methods}

Agarose (Roti ${ }^{\circledR}$ garose, Standard) was purchased from Roth, Karlsruhe, Germany. Phosphatebuffered saline (PBS), Dulbecco's Modified Eagle Medium (DMEM), fetal bovine serum (FBS), and penicillin/streptomycin were all purchased from BioChrom $\mathrm{GmbH}$, Berlin, Germany. 3-(4,5-Dimethylthiazol-2-yl)-2,5-diphenyltetrazolium bromide (MTT) was purchased from AppChem, Darmstadt, Germany. All other chemicals were of analytical grade and used as received from Merck, Darmstadt, Germany. The same batches of materials were used throughout the study.

\subsection{Preparation of Hydroxyapatite}

Aqueous solutions of $\mathrm{NH}_{4}\left(\mathrm{HPO}_{4}\right)_{2}\left(1 \mathrm{~mol} \mathrm{~L}^{-1}, 50 \mathrm{~mL}\right)$ and $\mathrm{NaOH}\left(1 \mathrm{~mol} \mathrm{~L}^{-1}, 64 \mathrm{~mL}\right)$ were added dropwise to $50 \mathrm{~mL}$ of an aqueous solution of $\mathrm{Ca}\left(\mathrm{NO}_{3}\right)_{2}\left(1.6 \mathrm{~mol} \mathrm{~L}^{-1}\right)$ under stirring at $1000 \mathrm{rpm}$ at $40{ }^{\circ} \mathrm{C}$ within $2 \mathrm{~h}$. Afterwards, the precipitated HA was stirred for an additional $22 \mathrm{~h}$ before washing with distilled water and collecting the precipitate by means of vacuum-filtration and subsequent lyophilization (Alpha 2-4LD plus, Christ, Osterode, Germany, $-82{ }^{\circ} \mathrm{C}, 0.1 \mathrm{mbar}$ ). The obtained powder was then treated in an oven (M104, Kendro Laboratory Products GmbH, Langenselbold, Germany) at $500{ }^{\circ} \mathrm{C}$ for $2 \mathrm{~h}$.

\subsection{Preparation of Agarose Gels}

Agarose $(0.4 \mathrm{~g})$ was dissolved in $20 \mathrm{~mL}$ Millipore water at $90^{\circ} \mathrm{C}$. After cooling to around $60^{\circ} \mathrm{C}$, the solution was cast into cylindrical molds $(16 \mathrm{~mm}$ diameter) and was allowed to cool down, solidifying in the process. The gels were cut into $10 \mathrm{~mm}$ high cylinders and subsequently used as hydrogels or dried via lyophilization or supercritical drying. For lyophilization, samples were 
frozen at $-40{ }^{\circ} \mathrm{C}$ and then dried at $-82{ }^{\circ} \mathrm{C}, 0.1 \mathrm{mbar}$. For supercritical drying, water was gradually replaced with ethanol in multiple steps, before being subjected to supercritical $\mathrm{CO}_{2}$.

\subsection{Preparation of $A G / H A$ Composites}

Agarose $(0.6 \mathrm{~g})$ was dissolved in $20 \mathrm{~mL}$ of a $0.2 \mathrm{~mol} \mathrm{~L}^{-1} \mathrm{Ca}\left(\mathrm{NO}_{3}\right)_{2}$ solution at $90^{\circ} \mathrm{C}$. After cooling to $60-70^{\circ} \mathrm{C}$, and $10 \mathrm{~mL}$ of $0.12 \mathrm{~mol} \mathrm{~L}^{-1} \mathrm{NH}_{4}\left(\mathrm{HPO}_{4}\right)_{2}$ and $0.16 \mathrm{~mol} \mathrm{~L}^{-1} \mathrm{NaOH}$ were added dropwise over $1 \mathrm{~h}$. The slurry was stirred at $600 \mathrm{rpm}$ for an additional $4 \mathrm{~h}$ at that temperature before casting the gels as described in Section 3.2. The cooled gels were then cut and dried similarly to the agarose gels. Scaffolds were prepared in the following polymer/ceramic mass ratios: AG100HA0 (2\%wt agarose in hydrogel), AG50HA50 (2\%wt agarose, $2 \%$ wt hydroxyapatite in hydrogel), and AG33HA67 (2\%wt agarose and $4 \%$ wt hydroxyapatite in hydrogel).

\subsection{Characterization of Scaffolds}

X-ray powder diffractograms were recorded with a D2 PHASER Diffractometer (Bruker AXS, Karlsruhe, Germany) with a $300 \mathrm{~W}$ X-ray tube $\left(\mathrm{Cu} \mathrm{K} \alpha, 2 \theta: 15-65^{\circ}\right)$. Samples were dried, pulverized, and analyzed independently. The diffractograms were compared with JCPDS PDF No. 09-432 for HA identification. Crystallite size has been evaluated using the Scherrer equation with the full width at half maximum of (002) signal, as measured with OriginPro 2016. The degree of crystallinity $\left(X_{c}\right)$ was calculated according to the literature by comparing the intensity of the valley between (112) and (300) $\mathrm{V}_{112 / 300}$ (Equation (1)) to the intensity of (300) $\mathrm{I}_{300}$ [55]:

$$
X_{c} \approx 1-\left(\frac{V_{112 / 300}}{I_{300}}\right)
$$

Fourier Transform-Infrared (FT-IR) measurements were performed with a FT/IR-410 spectrometer (Jasco, Tokyo, Japan) in absorbance mode with a resolution of $2 \mathrm{~cm}^{-1}$. Powdered samples were mixed with dried $\mathrm{KBr}$ and subsequently pressed into discs containing approximately $1 \% \mathrm{wt}$ of sample. Each spectrum was the result of 16 averaged scans.

A LEO 1450 VP scanning electron microscope by Zeiss, Oberkochen, Germany, with a resolution of $4 \mathrm{~nm}$ was used for recording micrographs of gold-sputtered samples after lyophilization or supercritical drying. For pore size evaluation, ImageJ software was used on the micrographs. A Bruker XFlash ${ }^{\circledR}$ 6 I60 QUANTAX EDS system (Bruker Nano GmbH, Berlin, Germany) was used for electron dispersive X-ray spectroscopy (EDX) analysis at $15 \mathrm{kV}$.

A Monosorb $^{\mathrm{TM}}$ (Quantachrome Instruments, Boyton Beach, FL, USA) BET gas ad-/de-sorption device (Brunauer-Emmett-Teller) with test gas $\mathrm{He}+30 \% \mathrm{~N}_{2}$ and adsorption with liquid $\mathrm{N}_{2}$ at $77 \mathrm{~K}$ was used on both lyophilized and supercritically-dried samples. Analysis was performed in triplicate with approximately $15 \mathrm{mg}$ of sample in each measurement. One-way ANOVA with the post hoc Tukey test with 95\% significance was performed on the data using OriginPro 2016 (OriginLab, Northampton, MA, USA).

Shrinking (by mass and volume) during drying was determined by taking the height, diameter, and weight of the native hydrogels and after drying using a caliper.

$$
\begin{gathered}
\operatorname{mass} \operatorname{loss}(\%)=\frac{m_{\text {wet }}-m_{d r y}}{m_{\text {wet }}} \\
\text { volume } \operatorname{loss}(\%)=\frac{V_{\text {wet }}-V_{d r y}}{V_{\text {wet }}}
\end{gathered}
$$

Similarly, swelling behavior (by volume) and water uptake of the hydrogels and dried samples were investigated by immersing the specimens in $20 \mathrm{~mL}$ of water ( $\mathrm{pH} 5.0$ and 9.0) or phosphate-buffered saline (PBS, pH 7.4) at room temperature. The swelling was measured by taking the height, diameter, and weight of the scaffolds before immersion and after defined intervals of time, wiping off the excess water with filter paper [56]. 


$$
\begin{gathered}
\text { water uptake }(\%)=\frac{\left|m_{d r y}-m_{\text {wet }}\right|}{m_{d r y}} \\
\operatorname{swelling}(\%)=\frac{\left|V_{d r y}-V_{\text {wet }}\right|}{V_{d r y}}
\end{gathered}
$$

A Zwick/Roell universal testing machine Z020 (Zwick/Roell, Ulm, Germany) with an AST $500 \mathrm{~N}$ load cell $\left(0.03 \mathrm{~N}\right.$ pre-load, crosshead speed $\left.1 \mathrm{~mm} \mathrm{~min}^{-1}\right)$ was used for unconfined uniaxial compression testing. Specimen were cut into approximately $10 \mathrm{~mm}$-high cylinders (exact height measured during analysis) and measured in triplicate at ambient conditions. The compression modulus was calculated after a Hookean model for lyophilized samples and a neo-Hookean model for hydrogels and rehydrated samples, respectively [49].

\subsection{Biocompatibility Testing}

One batch of AG100HA0 and AG33HA67 scaffolds was prepared for biocompatibility testing as followed: After gelation, gels were washed three times with $50 \mathrm{~mL}$ deionized water and two times with $50 \mathrm{~mL}$ ethanol:water (70:30) for solvent exchange and disinfection. Gels were then cut into small discs of 1-2 $\mathrm{mm}$ in height and $12 \mathrm{~mm}$ in diameter. Three of each were placed in sterile distilled water or PBS ( $\mathrm{pH}$ 7.4) for $48 \mathrm{~h}$ before lyophilization. Lyophilized scaffolds were incubated in triplicate for $76 \mathrm{~h}$ at $37^{\circ} \mathrm{C}, 5 \% \mathrm{CO}_{2}$ in a medium comprised of DMEM $+10 \% \mathrm{FBS}+100 \mathrm{U} \mathrm{mL}^{-1} / 100 \mu \mathrm{g} \mathrm{mL}^{-1}$ penicillin/streptomycin. After incubation, the medium was collected and used for the MTT assay. Human mesenchymal stem cells (hMSCs) from adipose tissue of a 35-year old female donor (Lw35) and cells of the osteosarcoma cell line MG-63 were seeded into a 96-well plates at 20,000 and 50,000 cells/well, respectively and were incubated with scaffold-incubated medium for $16 \mathrm{~h}$. Cells were then washed with PBS and cultivated with DMEM + additives (see above) $+0.5 \mathrm{mg} \mathrm{mL}^{-1}$ MTT for $4 \mathrm{~h}$. Living cells convert MTT into its insoluble formazan, indicated by a color change from yellow to violet. DMSO was used for cell lysis and dissolution of formazan crystals. Cell viability was measured with a photometer (Anthos 2010, Biochrom Ltd., Cambridge, UK) at $550 \mathrm{~nm}$.

\subsection{Drug Loading and Drug Release Test}

Lyophilized cylindrical scaffolds (approximately $10 \mathrm{~mm}$ high, $16 \mathrm{~mm}$ in diameter) were loaded with drug solution (aqueous ATP or suramin) using the "drop-in" technique of a known amount of drug and equilibrated for several hours at room temperature to allow homogeneous drug distribution in the scaffold. After that, scaffolds were lyophilized and stored at $2-8^{\circ} \mathrm{C}$. For release testing, three of each loaded scaffold were separately placed into $20 \mathrm{~mL}$ of water. At given time points, $500 \mu \mathrm{L}$ of release medium were collected and restocked with $500 \mu \mathrm{L}$ of water in order to maintain a constant release volume. Absorbance of the sample solution was measured via UV-Vis spectroscopy (UV-1650PC, Shimadzu, Duisburg, Germany) at the absorbance maxima $\lambda=255 \mathrm{~nm}$ and $313 \mathrm{~nm}$ for ATP and suramin, respectively. The release was monitored up to $96 \mathrm{~h}$, taking into account the restocking of release medium. All release curves were fitted to different models in order to evaluate the underlying mechanism. A Weibull release function was used for accurately describing the amount of drug $M$ released at time $t$ :

$$
M=M_{f} \cdot\left(1-e^{\left(\frac{-(t-T)^{b}}{a}\right)}\right) \quad \text { and } \quad \sqrt[b]{a}=q
$$

$M_{f}$ is the maximum amount of drug released; $T$ describes the latency time of the system, which is often (close to) zero; while $a$ represents a scaling parameter and $b$ the curve's form, respectively. In order to evaluate the kinetic parameters of release, usually a power law-based Korsmeyer-Peppas model or a first-order-exponential model is used. The latter is used as a straightforward approach to model release kinetics under sink conditions, which is given for all release studies presented.

$$
M=M_{f}-B \cdot e^{-k t}
$$


$M_{f}$ again describes the maximum amount released, $B=\left(M_{f}-M_{0}\right)$, with $M_{0}$ as the initial amount at $t=0$, ideally being zero, while $k$ is the release rate. The Korsmeyer-Peppas model can be used for estimating kinetic parameters by investigating the first $60 \%$ of the release curve:

$$
M=K \cdot t^{n}
$$

where $K$ is the release velocity constant and $n$ is the exponent of release, which is related to the release mechanism [53].

\section{Conclusions}

The present study showed a fast, facile, and cost-effective way to produce organic-inorganic biocomposites comprised of agarose and hydroxyapatite suitable for tissue engineering. The structure and hence the scaffold's properties can be tuned by varying the polymer/ceramic ratio and by different drying methods. A higher amount of hydroxyapatite improved stiffness against compressive force and formed stability upon drying and re-swelling. Composite scaffolds retained biocompatibility and showed no cytotoxic effect against both osteosarcoma MG-63 and hMSC (Lw35) cell lines. The influence of the drying method resulting in a preserved hydrogel network structure in supercritically-dried samples has interesting implications for tuning porosity in future studies. Small pores of just a few nanometers may be essential for successful vascularization, while larger pores facilitate cell in-growth and osteogenesis. Scaffolds were loaded with either ATP or suramin for drug release and exhibited initial burst release, but in the case of the composite, drug release slowed down for both water-soluble drugs and was sustained over four days. Further studies regarding the scaffold-drug interaction with a special focus on sustaining the drug release even longer and the investigation of other drugs, as well as scaffold degradation studies are still needed. With a specifically-tuned release profile, these scaffold systems may become potential candidates for bone tissue engineering and drug delivery applications.

Author Contributions: M.W. performed the experiments and data analysis, and wrote and formatted the manuscript. P.F.O. performed and analyzed the biocompatibility tests. M.G., T.H., E.T., and M.S. contributed materials, analysis tools, and conceived of and designed the experimental studies. All authors reviewed the manuscript and approved the final version.

Funding: This work was funded by the German Federal Ministry of Education and Research (BMBF) programs "IngenieurNachwuchs 2015" and "PersoImplant" (Grant No. 13FH019IX5), FHInvest (Grant No. 13FH158IN6), and BRSUGraduate Institute (scholarship for P.F.O.).

Acknowledgments: The authors thank F.Steiniger (University Hospital Jena, Germany) for help with the SEM measurements, D. Feuser (Bonn-Rhein-Sieg University of Applied Sciences, Germany) for help with release measurements, and M. Pickett (University of Tulsa, USA) for English language revision.

Conflicts of Interest: The authors declare no conflict of interest.

\section{Abbreviations}

The following abbreviations are used in this manuscript:

$\begin{array}{ll}\text { ATP } & \text { adenosine } 5^{\prime} \text {-triphosphate } \\ \text { BET } & \text { Brunauer-Emmett-Teller surface analysis } \\ \text { EDX } & \text { electron dispersive X-ray spectroscopy } \\ \text { HA } & \text { hydroxyapatite } \\ \text { hMSC } & \text { human mesenchymal stem cells } \\ \text { LYO } & \text { lyophilization } \\ \text { PBS } & \text { phosphate-buffered saline } \\ \text { SCD } & \text { supercritical drying } \\ \text { SEM } & \text { scanning electron microscopy } \\ \text { VD } & \text { vacuum dried }\end{array}$




\section{Appendix A}

Appendix A.1. EDX Analysis
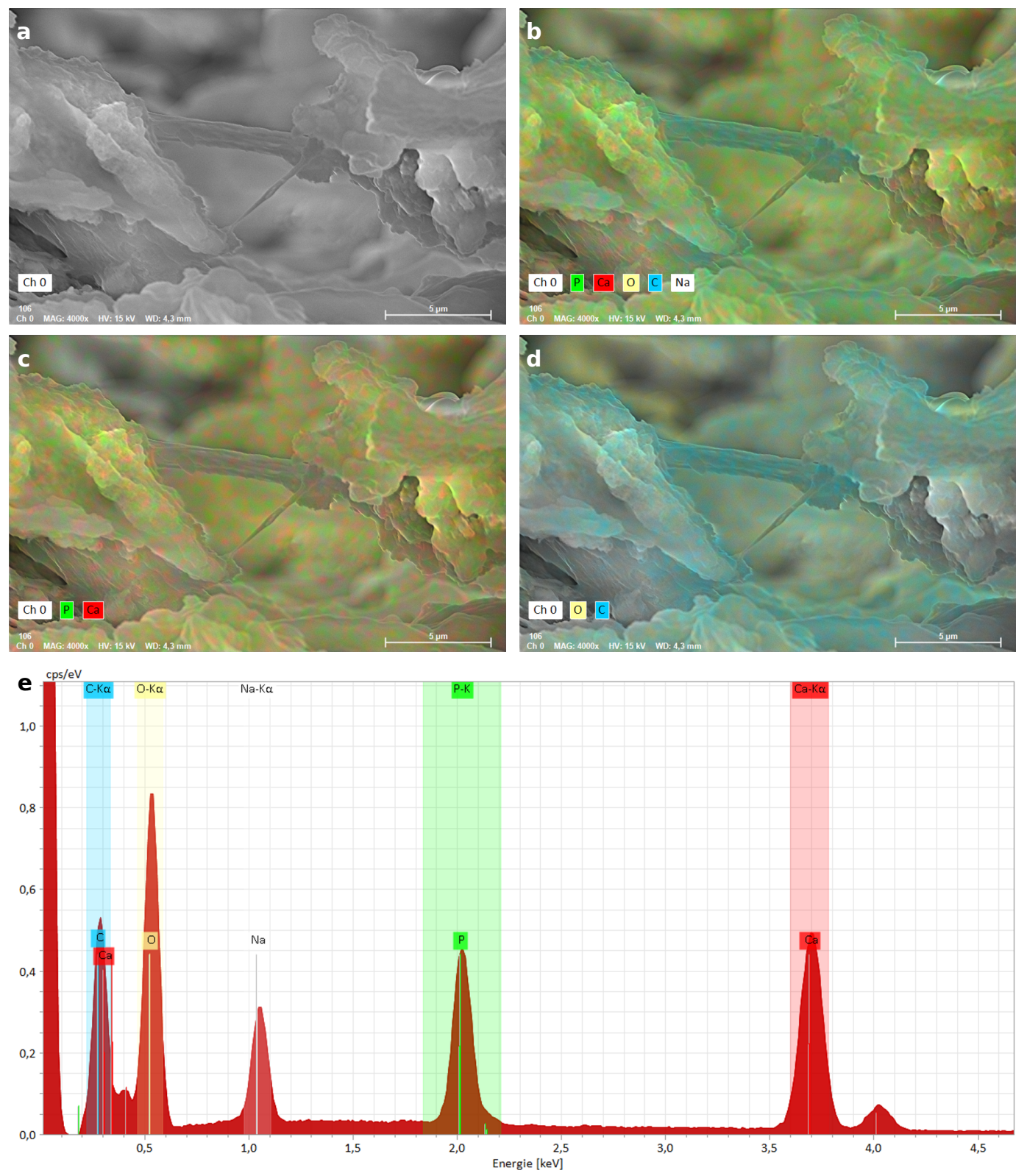

Figure A1. EDX mapping of a supercritically-dried AG33HA67 scaffold. (a) SEM picture; (b) mapping overlay of carbon (blue), calcium (red), phosphorus (green), oxygen (yellow), and sodium (white); (c) mapping overlay of calcium (red) and phosphorus (green); (d) mapping overlay of carbon (blue) and oxygen (yellow); (e) EDX spectrum of mapping data. The scale bar in mappings is $5 \mu \mathrm{m}$; voltage $15 \mathrm{kV}$; working distance $4.3 \mathrm{~mm}$. 
Appendix A.2. Swelling and Water Uptake Data
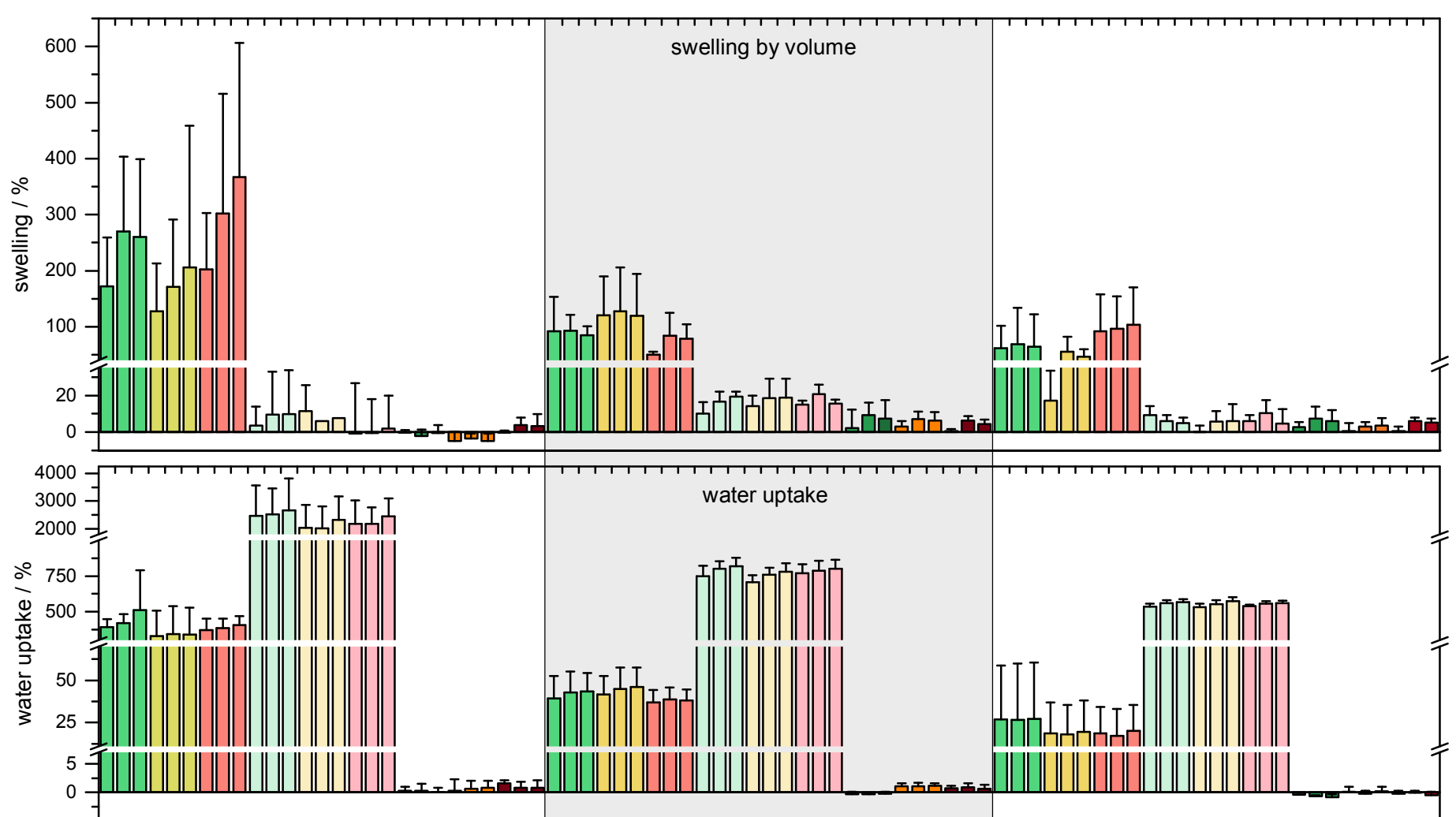

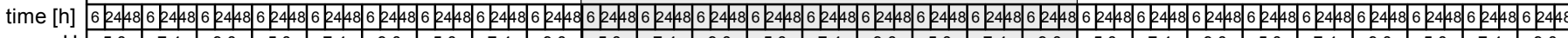
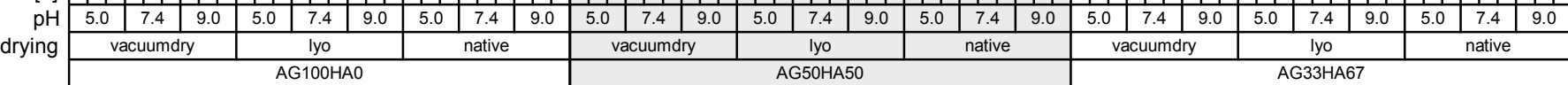

Figure A2. Complete dataset of swelling by volume and water uptake experiments. All three scaffolds were tested at different $\mathrm{pH}(5.0,7.4$, and 9.0$)$ over $48 \mathrm{~h}$ after different drying methods (vacuum drying, lyophilization, and as native hydrogel). 


\section{References}

1. Braddock, M.; Houston, P.; Campbell, C.; Ashcroft, P. Born Again Bone: Tissue Engineering for Bone Repair. Physiology 2001, 16, 208-213. [CrossRef]

2. Spicer, P.P.; Kretlow, J.D.; Young, S.; Jansen, J.A.; Kasper, F.K.; Mikos, A.G. Evaluation of Bone Regeneration Using the Rat Critical Size Calvarial Defect. NIH Public Access 2012, 7, 1918-1929. [CrossRef] [PubMed]

3. Grotheer, V.; Schulze, M.; Tobiasch, E. Trends in Bone Tissue Engineering: Proteins for Osteogenic Differentiation and the Respective Scaffolding. In Purification-Principles and Trends; iConcept Press Ltd.: Hong Kong, China, 2014; pp. 1-43.

4. Schulze, M.; Tobiasch, E. Artificial Scaffolds and Mesenchymal Stem Cells for Hard Tissues. In Tissue Engineering III: Cell-Surface Interactions for Tissue Culture; Kasper, C., Witte, F., Pörtner, R., Eds.; Springer: Berlin/Heidelberg, Germany, 2012; pp. 153-194. [CrossRef]

5. Rezwan, K.; Chen, Q.; Blaker, J.; Boccaccini, A.R. Biodegradable and Bioactive Porous Polymer/Inorganic Composite Scaffolds for Bone Tissue Engineering. Biomaterials 2006, 27, 3413-3431. [CrossRef] [PubMed]

6. Zakrzewski, W.; Dobrzyński, M.; Szymonowicz, M.; Rybak, Z. Stem Cells: Past, Present, and Future. Stem Cell Res. Ther. 2019, 10, 68. [CrossRef] [PubMed]

7. Andrzejewska, A.; Lukomska, B.; Janowski, M. Concise Review: Mesenchymal Stem Cells: From Roots to Boost. Stem Cells 2019, 37. [CrossRef]

8. Zippel, N.; Limbach, C.A.; Ratajski, N.; Urban, C.; Luparello, C.; Pansky, A.; Kassack, M.U.; Tobiasch, E. Purinergic Receptors Influence the Differentiation of Human Mesenchymal Stem Cells. Stem Cells Dev. 2012, 21, 884-900. [CrossRef]

9. Ciciarello, M.; Zini, R.; Rossi, L.; Salvestrini, V.; Ferrari, D.; Manfredini, R.; Lemoli, R.M. Extracellular Purines Promote the Differentiation of Human Bone Marrow-Derived Mesenchymal Stem Cells to the Osteogenic and Adipogenic Lineages. Stem Cells Dev. 2013, 22, 1097-1111. [CrossRef]

10. Burnstock, G. Purinergic Signalling: Therapeutic Developments. Front. Pharmacol. 2017, 8, 661. [CrossRef]

11. Ottensmeyer, P.; Witzler, M.; Schulze, M.; Tobiasch, E. Small Molecules Enhance Scaffold-Based Bone Grafts via Purinergic Receptor Signaling in Stem Cells. Int. J. Mol. Sci. 2018, 19, 3601. [CrossRef]

12. Leiendecker, A.; Witzleben, S.; Schulze, M.; Tobiasch, E. Template-Mediated Biomineralization for Bone Tissue Engineering. Curr. Stem Cell Res. Ther. 2016, 12, 103-123. [CrossRef]

13. Witzler, M.; Alzagameem, A.; Bergs, M.; Khaldi-Hansen, B.E.; Klein, S.E.; Hielscher, D.; Kamm, B.; Kreyenschmidt, J.; Tobiasch, E.; Schulze, M. Lignin-Derived Biomaterials for Drug Release and Tissue Engineering. Molecules 2018, 23, 1885. [CrossRef]

14. Leach, J.K.; Whitehead, J. Materials-Directed Differentiation of Mesenchymal Stem Cells for Tissue Engineering and Regeneration. ACS Biomater. Sci. Eng. 2018, 4, 1115-1127. [CrossRef]

15. Quelch, K.J.; Melick, R.; Bingham, P.J.; Mercuri, S.M. Chemical Composition of Human Bone. Arch. Oral Biol. 1983, 28, 665-674. [CrossRef]

16. Palmer, L.C.; Newcomb, C.J.; Kaltz, S.R.; Spoerke, E.D.; Stupp, S.I. Biomimetic Systems for Hydroxyapatite Mineralization Inspired By Bone and Enamel. Chem. Rev. 2008, 108, 4754-4783. [CrossRef]

17. Ginebra, M.P.; Canal, C.; Espanol, M.; Pastorino, D.; Montufar, E.B. Calcium Phosphate Cements as Drug Delivery Materials. Adv. Drug Deliv. Rev. 2012, 64, 1090-1110. [CrossRef]

18. Koutsopoulos, S. Synthesis and characterization of hydroxyapatite crystals: A review study on the analytical methods. J. Biomed. Mater. Res. 2002, 62, 600-612. [CrossRef]

19. Götz, W.; Tobiasch, E.; Witzleben, S.; Schulze, M. Effects of Silicon Compounds on Biomineralization, Osteogenesis, and Hard Tissue Formation. Pharmaceutics 2019, 11, 117. [CrossRef]

20. Babczyk, P.; Conzendorf, C.; Klose, J.; Schulze, M.; Harre, K.; Tobiasch, E. Stem Cells on Biomaterials for Synthetic Grafts to Promote Vascular Healing. J. Clin. Med. 2014, 3, 39-87. [CrossRef]

21. Vega, S.; Kwon, M.; Burdick, J. Recent Advances in Hydrogels for Cartilage Tissue Engineering. Eur. Cells Mater. 2017, 33, 59-75. [CrossRef]

22. Gkioni, K.; Leeuwenburgh, S.C.G.; Douglas, T.E.L.; Mikos, A.G.; Jansen, J.A. Mineralization of Hydrogels for Bone Regeneration. Tissue Eng. Part B Rev. 2010, 16, 577-585. [CrossRef]

23. Arnott, S.; Fulmer, A.; Scott, W.; Dea, I.; Moorhouse, R.; Rees, D. The Agarose Double Helix and its Function in Agarose Gel Structure. J. Mol. Biol. 1974, 90, 269-284. [CrossRef] 
24. Normand, V.; Lootens, D.L.; Amici, E.; Plucknett, K.P. New Insight into Agarose Gel Mechanical Properties. Biomacromolecules 2000, 1, 730-738. [CrossRef]

25. Zarrintaj, P.; Manouchehri, S.; Ahmadi, Z.; Saeb, M.R.; Urbanska, A.M.; Kaplan, D.L.; Mozafari, M. Agarose-based biomaterials for tissue engineering. Carbohydr. Polym. 2018, 187, 66-84. [CrossRef]

26. Tabata, M.; Shimoda, T.; Sugihara, K.; Ogomi, D.; Serizawa, T.; Akashi, M. Osteoconductive and Hemostatic Properties of Apatite Formed on/in Agarose Gel as a Bone-Grafting Material. J. Biomed. Mater. Res. 2003, 67B, 680-688. [CrossRef]

27. Schipper, D.; Babczyk, P.; Elsayed, F.; Klein, S.E.; Schulze, M.; Tobiasch, E. Chapter 21-The Effect of Nanostructured Surfaces on Stem Cell Fate. In Nanostructures for Novel Therapy; Ficai, D., Grumezescu, A.M., Eds.; Micro and Nano Technologies, Elsevier: Amsterdam, The Netherlands, 2017; pp. 567-589. [CrossRef]

28. Suzawa, Y.; Funaki, T.; Watanabe, J.; Iwai, S.; Yura, Y.; Nakano, T.; Umakoshi, Y.; Akashi, M. Regenerative Behavior of Biomineral/Agarose Composite Gels as Bone Grafting Materials in Rat Cranial Defects. J. Biomed. Mater. Res. Part A 2010, 93, 965-975. [CrossRef]

29. Suzawa, Y.; Kubo, N.; Iwai, S.; Yura, Y.; Ohgushi, H.; Akashi, M. Biomineral/Agarose Composite Gels Enhance Proliferation of Mesenchymal Stem Cells with Osteogenic Capability. Int. J. Mol. Sci. 2015, 16, 14245-14258. [CrossRef]

30. Kolanthai, E.; Dikeshwar Colon, V.S.; Sindu, P.A.; Chandra, V.S.; Karthikeyan, K.R.; Babu, M.S.; Sundaram, S.M.; Palanichamy, M.; Kalkura, S.N. Effect of Solvent; Enhancing the Wettability and Engineering the Porous Structure of a Calcium Phosphate/Agarose Composite for Drug Delivery. RSC Adv. 2015, 5, 18301-18311. [CrossRef]

31. Khanarian, N.T.; Haney, N.M.; Burga, R.A.; Lu, H.H. A Functional Agarose-Hydroxyapatite Scaffold for Osteochondral Interface Regeneration. Biomaterials 2012, 33, 5247-5258. [CrossRef]

32. Sánchez-Salcedo, S.; Nieto, A.; Vallet-Regí, M. Hydroxyapatite/ $\beta$-tricalcium Phosphate/Agarose Macroporous Scaffolds for Bone Tissue Engineering. Chem. Eng. J. 2008, 137, 62-71. [CrossRef]

33. Paris, J.; Román, J.; Manzano, M.; Cabañas, M.; Vallet-Regí, M. Tuning Dual-Drug Release From Composite Scaffolds for Bone Regeneration. Int. J. Pharm. 2015, 486, 30-37. [CrossRef]

34. Iwai, S.; Shimizu, H.; Suzawa, Y.; Akashi, M.; Yura, Y. Hydroxyapatite Agarose Composite Gels as a Biochemical Material for the Repair of Alveolar Bone Defects Due to Cleft Lip and Palate. J. Oral Maxillofac. Surg. Med. Pathol. 2014, 27, 637-644. [CrossRef]

35. Hu, J.; Zhu, Y.; Tong, H.; Shen, X.; Chen, L.; Ran, J. A Detailed Study of Homogeneous Agarose/Hydroxyapatite Nanocomposites for Load-Bearing Bone Tissue. Int. J. Biol. Macromol. 2016, 82, 134-143. [CrossRef]

36. Raina, D.B.; Larsson, D.; Mrkonjic, F.; Isaksson, H.; Kumar, A.; Lidgren, L.; Tägil, M. Gelatin- HydroxyapatiteCalcium Sulphate Based Biomaterial for Long Term Sustained Delivery of Bone Morphogenic Protein-2 and Zoledronic Acid for Increased Bone Formation: In-Vitro and In-Vivo Carrier Properties. J. Control. Release 2018, 272, 83-96. [CrossRef]

37. He, X.; Liu, Y.; Yuan, X.; Lu, L. Enhanced Healing of Rat Calvarial Defects With MSCs Loaded on BMP-2 Releasing Chitosan/Alginate/Hydroxyapatite Scaffolds. PLoS ONE 2014, 9. [CrossRef]

38. Kolanthai, E.; Abinaya Sindu, P.; Thanigai Arul, K.; Sarath Chandra, V.; Manikandan, E.; Narayana Kalkura, S. Agarose Encapsulated Mesoporous Carbonated Hydroxyapatite Nanocomposites Powder for Drug Delivery. J. Photochem. Photobiol. B Biol. 2017, 166, 220-231. [CrossRef]

39. Kuriakose, T.; Kalkura, S.; Palanichamy, M.; Arivuoli, D.; Dierks, K.; Bocelli, G.; Betzel, C. Synthesis of Stoichiometric Nano Crystalline Hydroxyapatite by Ethanol-Based Sol-Gel Technique at Low Temperature. J. Cryst. Growth 2004, 263, 517-523. [CrossRef]

40. Socrates, G. Infrared and Raman Characteristic Group Frequencies: Tables and Charts, 3rd ed.; John Wiley \& Sons: Chichester, UK, 2008.

41. Antonakos, A.; Liarokapis, E.; Leventouri, T. Micro-Raman and FTIR Studies of Synthetic and Natural Apatites. Biomaterials 2007, 28, 3043-3054. [CrossRef]

42. Ren, F.; Ding, Y.; Leng, Y. Infrared Spectroscopic Characterization of Carbonated Apatite: A Combined Experimental and Computational Study. J. Biomed. Mater. Res. Part A 2014, 102, 496-505. [CrossRef]

43. Román, J.; Cabañas, M.V.; Peña, J.; Vallet-Regí, M. Control of the Pore Architecture in Three-Dimensional Hydroxyapatite-Reinforced Hydrogel Scaffolds. Sci. Technol. Adv. Mater. 2011, 12, 045003. [CrossRef] 
44. Kolanthai, E.; Ganesan, K.; Epple, M.; Kalkura, S.N. Synthesis of Nanosized Hydroxyapatite/Agarose Powders for Bone Filler and Drug Delivery Application. Mater. Today Commun. 2016, 8, 31-40. [CrossRef]

45. García-González, C.; Alnaief, M.; Smirnova, I. Polysaccharide-Based Aerogels_Promising Biodegradable Carriers for Drug Delivery Systems. Carbohydr. Polym. 2011, 86, 1425-1438. [CrossRef]

46. Robitzer, M.; Tourrette, A.; Horga, R.; Valentin, R.; Boissière, M.; Devoisselle, J.; Di Renzo, F.; Quignard, F. Nitrogen Sorption as a Tool for the Characterisation of Polysaccharide Aerogels. Carbohydr. Polym. 2011, 85, 44-53. [CrossRef]

47. Reverchon, E.; Pisanti, P.; Cardea, S. Nanostructured PLLA-Hydroxyapatite Scaffolds Produced by a Supercritical Assisted Technique. Ind. Eng. Chem. Res. 2009, 48, 5310-5316. [CrossRef]

48. Velasco, M.A.; Narváez-Tovar, C.A.; Garzón-Alvarado, D.A. Design, Materials, and Mechanobiology of Biodegradable Scaffolds for Bone Tissue Engineering. BioMed Res. Int. 2015, 2015, 1-21. [CrossRef]

49. Oyen, M.L. Mechanical Characterisation of Hydrogel Materials. Int. Mater. Rev. 2014, 59, 44-59. [CrossRef]

50. DeKosky, B.J.; Dormer, N.H.; Ingavle, G.C.; Roatch, C.H.; Lomakin, J.; Detamore, M.S.; Gehrke, S.H. Hierarchically Designed Agarose and Poly(Ethylene Glycol) Interpenetrating Network Hydrogels for Cartilage Tissue Engineering. Tissue Eng. Part C Methods 2010, 16, 1533-1542. [CrossRef]

51. Karageorgiou, V.; Kaplan, D. Porosity of 3D Biomaterial Scaffolds and Osteogenesis. Biomaterials 2005, 26, 5474-5491. [CrossRef]

52. Mehdizadeh, H.; Sumo, S.; Bayrak, E.S.; Brey, E.M.; Cinar, A. Three-Dimensional Modeling of Angiogenesis in Porous Biomaterial Scaffolds. Biomaterials 2013, 34, 2875-2887. [CrossRef]

53. Bruschi, M.L. Strategies to Modify the Drug Release from Pharmaceutical Systems; Woodhead Publishing: Cambridge, UK, 2015.

54. Gelardi, G.; Mantellato, S.; Marchon, D.; Palacios, M.; Eberhardt, A.; Flatt, R. Chemistry of Chemical Admixtures. In Science and Technology of Concrete Admixtures; Elsevier: Amsterdam, The Netherlands, 2016; pp. 149-218. [CrossRef]

55. Landi, E.; Tampieri, A.; Celotti, G.; Sprio, S. Densification Behaviour and Mechanisms of Synthetic Hydroxyapatites. J. Eur. Ceram. Soc. 2000, 20, 2377-2387. [CrossRef]

56. Román, J.; Cabañas, M.; Peña, J.; Doadrio, J.; Vallet-Regí, M. An Optimized $\beta$-tricalcium Phosphate and Agarose Scaffold Fabrication Technique. J. Biomed. Mater. Res. Part A 2008, 84, 99-107. [CrossRef]

(C) 2019 by the authors. Licensee MDPI, Basel, Switzerland. This article is an open access article distributed under the terms and conditions of the Creative Commons Attribution (CC BY) license (http:/ / creativecommons.org/licenses/by/4.0/). 